\title{
Unusual case of anorexia
}

\author{
Laura Darmaun, ${ }^{1}$ Estelle Aubry, ${ }^{2}$ Sophie Lejeune, ${ }^{3}$ Helene Sudour-Bonnange ${ }^{4}$
}

'Department of Pediatrics, Jeanne de Flandres hospital, CHRU Lille, Lille, France ${ }^{2}$ Department of Pediatric Digestive Surgery, Centre Hospitalier Regional Universitaire de Lille, Lille, France

${ }^{3}$ Department of genetics, CHRU Lille, Lille, France

${ }^{4}$ Pediatric and AYA oncology Unit, oscar lambret center, lille, France

\section{Correspondence to}

Dr Helene Sudour-Bonnange, h-sudour@o-lambret.fr

Accepted 29 April 2018
Check for updates

To cite: Darmaun L, Aubry E, Lejeune $\mathrm{S}$, et al. BMJ Case Rep Published Online First: [please include Day Month Year]. doi:10.1136/bcr-2017223739

\section{SUMMARY}

We report the case of a 15-year-old female patient suffering from progressive anorexia, weight loss and recurrent abdominal pain, initially diagnosed as anorexia nervosa. She eventually presented with severe malnutrition and acute bowel obstruction, revealing a mass of the transverse colon. A well-differentiated Lieberkühn adenocarcinoma was established by histology. The patient underwent transverse and right colectomy and was treated with adjuvant chemotherapy. Colorectal cancer (CRC) is predominantly a disease of older adults and is extremely rare in children and adolescents. Seldom suspected, it is more likely to be diagnosed at an advanced stage, with unfavourable tumour histology and poor outcome. Young patients diagnosed with CRC should receive genetic counselling regardless of their family history or tumour type. This reports' take-home message is that recurrent and persistent digestive symptoms in the young should alert physicians and lead to further investigations.

\section{BACKGROUND}

In children and adolescents, anorexia can be a common symptom of acute gastrointestinal or infectious diseases and can also be a relevant sign of a chronic organic disorder. Anorexia nervosa is a severe disease affecting body image, its diagnosis requires precise criteria and a specific psychological profile. $^{1}$

We report the case of a teenage patient initially diagnosed as presenting an 'anorexia nervosa', who was actually suffering from an adenocarcinoma of the transverse colon.

\section{CASE PRESENTATION}

A 15-year-old Caucasian female patient presented with a year long history of insidious and progressive deterioration of general condition, anorexia and recurrent diffuse abdominal pain. The patient had no personal history. Her family history included a colorectal cancer (CRC) in her grandfather, who had died 5 years before. She had social, scholar and family issues, with major psychological tensions between her and her father, that had been going on for months. She visited her family practitioner once only, a few months before the onset of abdominal pain. He observed an association of weight loss and progressive anorexia. Hence the social, family and psychological background which he was aware of, he concluded in depression and anorexia nervosa without further investigation. After a year, the development of abdominal pain associated with occasional vomiting and constipation, led to a first series of examinations (basic blood tests, chest radiography and abdominal ultrasound) which were found normal. A few weeks later, she was admitted to our university hospital for repetitive vomiting. She reported amenorrhoea in the past 4 months. Physical examination showed cachexia, pallor and bilateral leg oedema. She had lost $10 \mathrm{~kg}$ in a year ( $25 \%$ of her original weight) and had a body mass index of 13.7 .

\section{INVESTIGATIONS}

Biology showed severe hypoalbuminaemia (14 g/L) and hypocalcaemia $(76 \mathrm{mg} / \mathrm{L})$. Upright abdominal X-ray (figure 1) showed dilated loops of bowel suggesting intestinal obstruction. An abdominal CT with contrast enhancement showed a suspicious mass of the transverse colon, with dilatation of the upper end of the colon (figure 2). Colonoscopy revealed a granulating, ulcerated and stenotic mass of the transverse colon. Pathology revealed malignant proliferation of grouped glands, with cylindrical cells containing atypical and laminated nuclei and mucin lakes, infiltrating the muscle mucosa. Rectum biopsies were free of tumour infiltration. Thoracic, abdominal and pelvic CT found no distant metastatic localisation.

A transverse and right colectomy with lymph node dissection was performed. On pathology, a $7.5 \mathrm{~cm}$, well-differentiated Lieberkühn adenocarcinoma of the transverse colon was found, invading the entire colon wall and reaching the peritoneum. Only one lymph node out of 50 was involved with tumour proliferation. Excision margins were healthy. The tumour was graded pT4N1M0 according to the 7 th TNM classification.

In our patient, immunohistochemistry showed a defect in the expression of proteins MSH2 and MSH6, and the RER phenotype analysis detected microinstability in more than half of the markers tested. Constitutional genetic analysis showed a variant of unknown significance of the MSH2 gene suspected to be a splice variant. Given these results, we concluded in the diagnosis of Lynch Syndrome and we proposed a specific medical follow-up: colonoscopy every 1-2 years, then gynaecological examination with transvaginal ultrasound every $1-2$ years starting at age $30 .^{2-4}$

\section{TREATMENT}

The patient received parenteral nutritional support for a month, then adjuvant chemotherapy (5-fluorouracil and oxaliplatin) for 6 months. Three years following surgery, she remains in remission. 


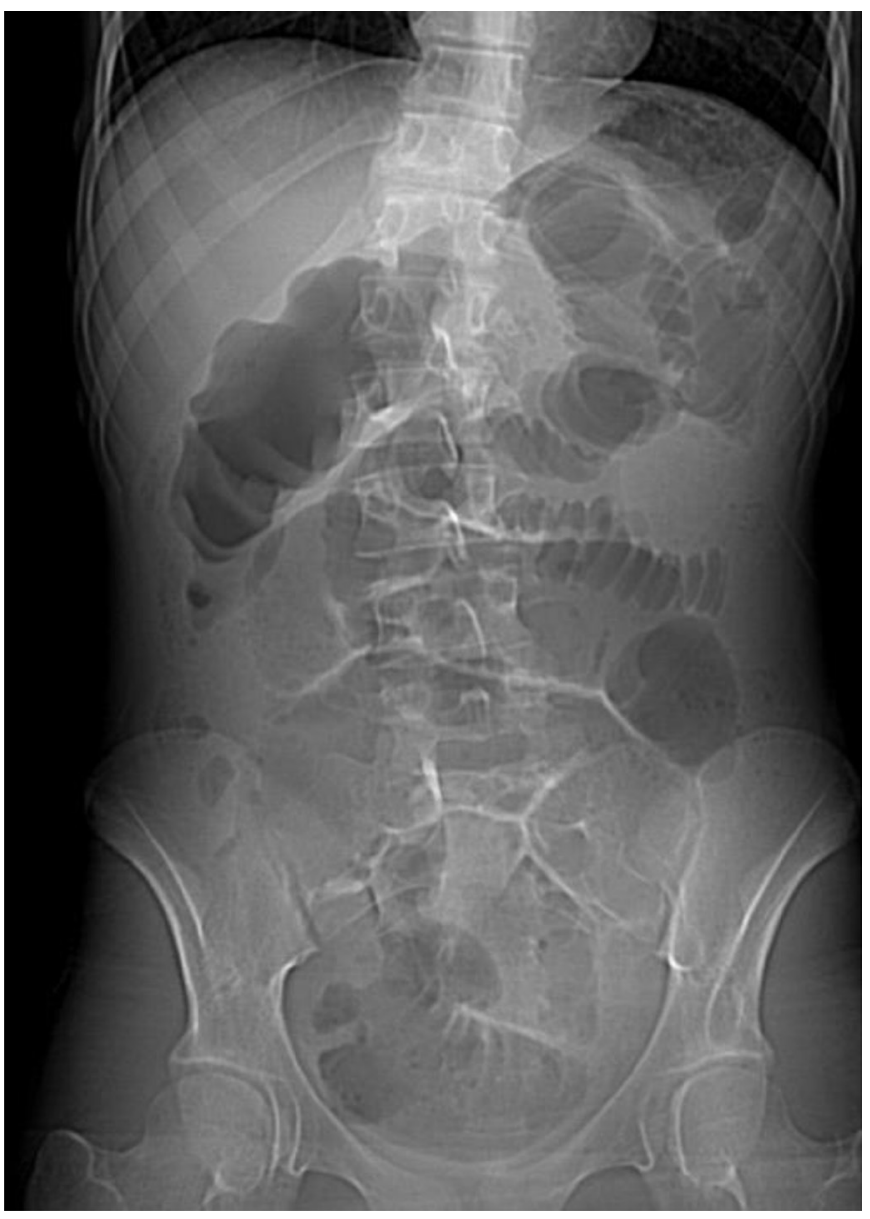

Figure 1 Upright abdominal X-ray showing dilated loops of bowel.

\section{DISCUSSION}

CRC is exceedingly rare in children and teenagers, especially when they have no underlying risk factors such as familial adenomatous polyposis, hereditary non-polyposis colon cancer (HNPCC=Lynch) and constitutive mismatch repair deficiency (CMMRD). It is generally a disease of older patients, with $90 \%$ diagnosed after the age of 50 years. ${ }^{56}$ The Surveillance,

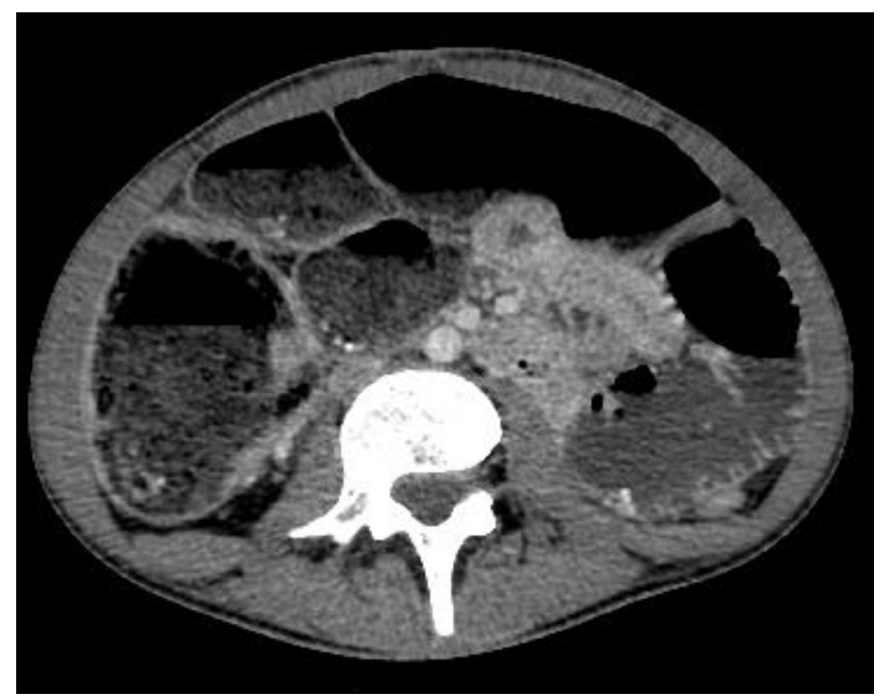

Figure 2 Abdominal CT showing a mass of the transverse colon, with dilatation of the upper end of the colon.
Epidemiology and End Results (SEER) programme reported about 80 new cases a year in patients less than 20 years of age in USA (among 150000 cases of all ages), with an estimated annual incidence of approximately 1 case per million individuals in children. ${ }^{7}$ For children, adolescents and young adults (AYA), age at diagnosis generally ranges from 12 to 18 years of age, ${ }^{7-11}$ with a median age around 15 . $^{79}$

First symptoms are vague and unspecific: ${ }^{9-12}$ abdominal pain (79\%-85\%), weight loss (25\%-65\%), anorexia (25\%), anaemia (77\%), vomiting (50\%) and altered bowel habits such as constipation (26\%) and diarrhoea (22\%). Although rapidly suspected in adults, they are often underestimated in children and AYA because of their young age. ${ }^{910}$ Limited awareness for CRC in young patients often misleads physicians to a more common aetiology, such as colitis, appendicitis, functional colopathy or constipation. ${ }^{13}$ Diagnosis is often delayed, which is why children and teenagers with CRC usually present a more advanced disease on diagnosis, hence a poorer prognosis. ${ }^{8}$

Recurrent abdominal pain involves $9 \%-15 \%$ of adolescents, ${ }^{13}$ particularly teenage female, and over $60 \%$ is attributed to psychosomatic aetiologies. ${ }^{14}$ Extreme caution should be taken to separate functional from organic causes, ${ }^{13}$ especially if the recurrent pain is associated with progressive anorexia and weight loss.

Diagnosis and staging of CRC requires colonoscopy and imaging and is confirmed by histology. ${ }^{12}$ Thoracic and pelvic CT are required to assess tumour extension and search for distant metastatic localisations.

Following adult guidelines, treatment includes complete surgical resection of the diseased colonic segment, followed by a precise lymph node dissection, as performed in our patient. Resection margins should be free of cancer cells to allow complete recovery. Adjuvant multiagent chemotherapy is used for high risk localisations or advanced stage disease, as it was for our patient. Chemotherapy is based on a fluorouracil backbone, oxaliplatin or irinotecan. Radiotherapy is reserved for rectal localisation and palliative treatment. ${ }^{1516}$

In children and adolescents, the most common histological type of CRC is poorly differentiated mucinous adenocarcinoma, with particularly aggressive behaviour. ${ }^{7-9} 13$ Advanced stage on diagnosis may contribute to the unsatisfactory outcome of young patients with CRC: their 5-year survival rate is reported of $40 \%$ vs $60 \% \pm 0.10 \%$ for adults. ${ }^{8}$ The 10 -year survival estimate ranges from $20.1 \pm 5.4 \%$ to $57.9 \% .^{79}$ A multivariate analysis in 2010 identified tumour stage $(H R=8.39, p<0.001$ for distant disease), tumour type (signet ring $\mathrm{HR}=2.12, \mathrm{p}=0.025$ and carcinoid $\mathrm{HR}=0.14, \mathrm{p}=0.001$ ) and surgical resection (no surgery $\mathrm{HR}=2.98, \mathrm{p}=0.010$ ) as independent predictors of worse outcome. ${ }^{8}$ A recent study suggested that the presence of a genetic tumour syndrome $(p=0.019)$, absence of peritoneal spreading $(p<0.001)$, tumour stages I-III $(p<0.001)$ and complete resection $(\mathrm{R} 0 ; \mathrm{p}<0.001)$ were significant positive predictors of survival. $^{11}$

Recent studies show that approximately $35 \%$ of children and AYA with CRC are tested positive for genetic tumour predisposition ${ }^{11} 17$ and $19 \%$ of the hereditary syndromes were diagnosed in individuals with no family history of the disease. ${ }^{17}$ HNPCC or Lynch syndrome is the most common of inherited CRC, accounting for $2 \%-4 \%$ of CRC. ${ }^{2}$ It is a predisposition to develop colorectal, endometrial and various other cancers, which often arise at young ages. It is caused by germline mutations in one of the DNA mismatch repair (MMR) genes. ${ }^{2}$ CMMRD is a rare condition due to biallelic MMR gene defect with a high risk of various malignancies from early age: haematological 
malignancies and central nervous system tumours in the first decade, CRC in the second decade.

\section{Learning points}

- Recurrent digestive symptoms combined with progressive deterioration of general health condition should always alert paediatricians and family physicians.

- Earlier diagnosis of colorectal cancer (CRC) and a quick referral to expert professionals could allow those patients a more favourable prognosis.

- When diagnosed with CRC, patients age 35 years or younger should receive genetic counselling regardless of their family history and phenotype.

- A multidisciplinary team is necessary to give these young patients the best care and to ensure social, scholar and professional integration further on. ${ }^{1819}$

Contributors LD, EA, SL and HS-B treated the patient. LD designed the study, collected the data and wrote the case report. HS-B developed the idea, supervised the writing and provided guidance in all steps. EA and SL critically revised the case report for accuracy and appropriateness of intellectual content and served as scientific advisors

Funding The authors have not declared a specific grant for this research from any funding agency in the public, commercial or not-for-profit sectors.

Competing interests None declared.

Patient consent Obtained.

Provenance and peer review Not commissioned; externally peer reviewed.

(c) BMJ Publishing Group Ltd (unless otherwise stated in the text of the article) 2018. All rights reserved. No commercial use is permitted unless otherwise expressly granted.

\section{REFERENCES}

1 DSM-V American Psychiatric Association. Diagnostic and Statistical Manual of Mental Disorders, 2014

2 Stoffel EM, Kastrinos F. Familial colorectal cancer, beyond Lynch syndrome. Clin Gastroenterol Hepatol 2014;12:1059-68.
3 Giardiello FM, Allen Jl, Axilbund JE, et al. Guidelines on genetic evaluation and management of Lynch syndrome: a consensus statement by the US Multi-Society Task Force on Colorectal Cancer. Dis Colon Rectum 2014;57:1025-48.

4 Gupta S, Provenzale D, Regenbogen SE, et al. NCCN Guidelines Insights: Geneticl Familial High-Risk Assessment: Colorectal, Version 3.2017. J Natl Compr Canc Netw 2017:15:1465-75

5 Liang J, Kalady MF, Church J. Young age of onset colorectal cancers. Int I Colorectal Dis 2015:30:1653-7.

6 Globocan 2012: Estimated Cancer Incidence, Mortality and Prevalence Worldwide in 2012. http://globocan.iarc.fr.

7 Yang R, Cheung MC, Zhuge Y, et al. Primary solid tumors of the colon and rectum in the pediatric patient: a review of 270 cases. J Surg Res 2010;161:209-16.

8 Sultan I, Rodriguez-Galindo C, El-Taani H, et al. Distinct features of colorectal cancer in children and adolescents: a population-based study of 159 cases. Cancer 2010;116:758-65.

9 Hill DA, Furman WL, Billups CA, et al. Colorectal carcinoma in childhood and adolescence: a clinicopathologic review. J Clin Oncol 2007;25:5808-14.

10 Tay $\mathrm{CH}$, Lee $\mathrm{HC}$, Yeung $\mathrm{CY}$, et al. Different clinical manifestations between primary gastrointestinal malignancies and benign tumors in children. J Pediatr Gastroenterol Nutr 2012:55:440-4.

11. Weber ML, Schneider DT, Offenmüller S, et al. Pediatric colorectal carcinoma is associated with excellent outcome in the context of cancer predisposition syndromes. Pediatr Blood Cancer 2016:63:611-7.

12 Blumer SL, Anupindi SA, Adamson PC, et al. Sporadic adenocarcinoma of the colon in children: case series and review of the literature. J Pediatr Hematol Oncol 2012;34:e137-41.

13 Bjoernsen LP, Lindsay MB. An unusual case of pediatric abdominal pain. CJEM 2011;13:133-8.

14 Alfvén G. One hundred cases of recurrent abdominal pain in children: diagnostic procedures and criteria for a psychosomatic diagnosis. Acta Paediatr 2003;92:43-9.

15 HAS. Cancer colorectal adénocarcinome january 2012. http://www.has-sante.fr/ portail/upload/docs/application/pdf/2012-03/ald_30 guide_ccr_web.pdf

16 National Comprehensive Cancer Network, 2011 https://www.nccn.org/professionals/ physician gls/f guidelines.asp\#colon

17 Mork ME, You YN, Ying J, et al. High prevalence of hereditary cancer syndromes in adolescents and young adults with colorectal cancer. J Clin Oncol 2015;33:3544-9.

18 Fernandez C, Fraser GA, Freeman C, et al. Principles and recommendations for the provision of healthcare in canada to adolescent and young adult-aged cancer patients and survivors. J Adolesc Young Adult Oncol 2011;1:53-9.

19 Rogers $\mathrm{PC}$, De Pauw S, Schacter B, et al. A process for change in the care of adolescents and young adults with cancer in canada. "moving to action": The second canadian international workshop. International perspectives on AYAO, Part 1. J Adolesc Young Adult Oncol 2013;2:72-6.

Copyright 2018 BMJ Publishing Group. All rights reserved. For permission to reuse any of this content visit

http://group.bmj.com/group/rights-licensing/permissions.

BMJ Case Report Fellows may re-use this article for personal use and teaching without any further permission.

Become a Fellow of BMJ Case Reports today and you can:

- Submit as many cases as you like

- Enjoy fast sympathetic peer review and rapid publication of accepted articles

- Access all the published articles

- Re-use any of the published material for personal use and teaching without further permission

For information on Institutional Fellowships contact consortiasales@bmjgroup.com

Visit casereports.bmj.com for more articles like this and to become a Fellow 